\title{
PALABRAS DE BIENVENIDA A LA JORNADA LXXVI ANIVERSARIO DE LA SOCIEDAD VENEZOLANA DE CIRUGIA
}

\author{
JOSÉ FÉLIX VIVAS
}

\section{Queridos amigos:}

En representación de la Junta Directiva de la Sociedad Venezolana de Cirugía me ha correspondido el honor de manifestar estas palabras de bienvenida a nuestra Jornada para celebrar el LXXVI aniversario de la Sociedad.

La Sociedad Venezolana de Cirugía se fundó el 20 de octubre de 1944, cuando se firmó el acta fundacional, con la firma de 53 de los cirujanos más prestigiosos de todo el país y que constituyen el privilegiado grupo de miembros fundadores. En Venezuela se celebra este día como el Día del Cirujano, en recuerdo a la fundación de la Sociedad. Si bien, el acta fundacional se firmó el 20 de octubre de 1944, la Sociedad Venezolana de Cirugía comenzó sus actividades en 1945, con la primera Junta Directiva que se encargó de establecer los cimientos para el funcionamiento posterior de nuestra Sociedad.

Se inició esta gesta cuando un grupo de jóvenes cirujanos del Hospital Vargas de Caracas, después de haber obtenido por concurso de oposición, cargos como adjuntos de cirugía en el mes de junio de 1944, en la celebración para tal ocasión en el Club Paraíso de Caracas, surgió la idea de fundar una sociedad quirúrgica digna de nuestro país, para lo cual escogieron como primer presidente al profesor de cirugía que valoraron con el mayor prestigio por su reconocida honestidad y calidad científica y docente: el profesor Domingo Luciani, eminente cirujano, considerado la sexta y última cumbre quirúrgica en nuestro país por el historiador médico Francisco Plaza Izquierdo.

Esta primera Junta Directiva estuvo conformada por 6 ilustres jóvenes cirujanos, presididos por el profesor Luciani, para un período de un año 1945 -1946. Los reglamentos y estatutos fueron establecidos utilizando como modelo a los de la prestigiosa Academia Francesa de Cirugía. La juramentación de esta junta fue en un solemne acto académico realizado en el paraninfo de la antigua Universidad Central de Venezuela, actual Palacio de la Academias.

La primera sociedad quirúrgica académica que se tiene conocimiento, fue el Colegio Real de Cirujanos de Londres en el año 1800, a esta sociedad perteneció nuestro ilustre padre de la medicina y la cirugía en Venezuela, el doctor José María
Vargas. En Latinoamérica, las primeras asociaciones quirúrgicas fueron la brasilera y la cubana en 1929. En 1930 se fundó la argentina; posteriormente la uruguaya en 1942 y luego la venezolana en 1944. Podemos afirmar que la Sociedad Venezolana de Cirugía, gracias a la visión de sus fundadores, fue pionera en nuestra región, dándole un gran empuje a la cirugía venezolana.

La primera sede de la sociedad fue en los recintos del Colegio Médico de Caracas, en la denominada Plaza Las Tres Gracias, frente a la Universidad Central de Venezuela. Allí también se efectuaron las actividades académicas, jornadas, congresos. Después estuvimos en la Torre del Colegio Médico del Distrito Federal, hasta mudarnos a nuestra sede propia en el año 2005

El primer Congreso Venezolano de Cirugía se realizó en el año 1951, en el antiguo Colegio Médico del Distrito Federal en Caracas, con una asistencia masiva que colmó el auditorio y un relato oficial dedicado a la cirugía biliar, presentado por el doctor Ricardo Baquero. Actualmente estamos ya por el XXXV Congreso, que no se pudo realizar por las terribles circunstancias que estamos viviendo. Este congreso estaba pautado para el mes de junio de este año y se tuvo que suspender, esperando poder realizarlo para marzo de 2021 y de acuerdo a como se vayan presentando los acontecimientos.

Para esta jornada aniversario, quisimos dedicarla a un tema de importantísima actualidad, como es la pandemia por coronavirus y sus efectos en el ejercicio de la cirugía. Para ello hemos podido reunir un grupo de expertos, tanto nacionales como internacionales, quienes nos mostrarán sus experiencias en el manejo de pacientes quirúrgicos. Trataremos temas de gran vigencia y actualidad como son los protocolos del quirófano, manejo de las patologías quirúrgicas más frecuentes, la cirugía bariátrica y de mínima invasión, la patología oncológica cuya resolución se ha visto afectada por las consecuencias del COVID-19; tendremos una conferencia magistral que tratará sobre la utilidad de las redes sociales en el marco de la pandemia, y habrá también una interesante disertación acerca del agotamiento de los residentes de cirugía durante todo este tiempo que ha durado la propagación de la enfermedad, y sus efectos en el proceso de aprendizaje. Para 
ello hemos seleccionado un grupo de residentes de varias partes del país, que además sufrieron el contagio por el coronavirus, para que nos compartan sus experiencias.

Esta es nuestra primera jornada virtual grande. Hemos realizado un esfuerzo inmenso para el éxito de la actividad. La receptividad ha sido masiva, con más de 700 inscritos, superando en grande nuestras expectativas. Esperamos dentro de las grandes dificultades que nos aquejan, el éxito de la jornada y que los problemas que se puedan presentar en un país donde sabemos que fallan muchas cosas, podamos subsanarlos y controlarlos para que el evento se desarrolle y fluya con normalidad y todos podamos disfrutar del conocimiento impartido.

La pandemia del coronavirus ha afectado con especial severidad al personal sanitario en Venezuela. La mortalidad es una de las más altas del mundo y de la región. Le escasez de los equipos de protección personal y su uso inadecuado han sido señalados como la principal causa de esta altísima mortalidad que está por el orden del 25 - 30 \% de todos los fallecidos por COVID-19 en el país.

Aunque no se cuentan con cifras oficiales, la Federación Médica Venezolana y organizaciones como Médicos Unidos Venezolanos han realizado un seguimiento y registrado todos los casos y así vemos que el estado Zulia es el que más ha sufrido las consecuencias de esta pandemia, seguido por la región capital y los estados Bolívar, Carabobo, Aragua y Barinas.

Cuando se analizan estos lamentables fallecimientos por especialidad, observamos que la gran mayoría de estos colegas fallecidos ejercían su especialidad en el ambiente quirúrgico. Obstetras, cirujanos, traumatólogos, anestesiólogos neurocirujanos y urólogos han sido los más afectados en estas tristes estadísticas. De ahí la importancia de realizar una jornada dedicada a este tema que tan funestos resultados ha ocasionado.

Y cuando la tragedia te toca tan de cerca es cuando duele más. Recientemente tuvimos la nefasta noticia del fallecimiento de nuestro querido compañero José Alberto Rosales, Tico, cirujano muy apreciado de Barinas, donde era el presidente del Capítulo Barinas y Miembro Honorario de la Sociedad. El doctor Rosales venía desarrollando una extraordinaria labor en su estado, asistía a su servicio, apoyando a los residentes y al postgrado, y lamentablemente sucumbió ante el contagio con el coronavirus después de una terrible y prolongada batalla. Muy triste para todos nosotros fue esta dolorosa pérdida. José Alberto fue una excepcional persona, siempre al servicio de sus pacientes y de su familia, donde fundó un hermoso hogar, todos cirujanos: su esposa y sus dos hijos. Al doctor José Alberto Rosales le dedicamos esta Jornada, a su recuerdo y legado. Era mucho lo que tenía que aportar Tico, pero el destino le hizo una mala jugada. Queda en nosotros y en su familia, colegas y amigos mantener ese legado y esa dedicación que Rosales siempre le impuso a sus actividades.
La Junta Directiva de la Sociedad Venezolana de Cirugía y el Comité Organizador, agradece a las casas comerciales que nos han dado su apoyo para esta realización, así como a la empresa organizadora de eventos AJProducciones, en la persona de su directora Alejandra Jiménez. Sin ellos no hubiéramos podido lograr esta Jornada Aniversario. Muchas gracias a ustedes por su asistencia y nuestros deseos para que la actividad sea de provecho a todos los participantes.

\section{Enlace a vídeo del Discurso:}

https://youtu.be/wKbv5VYtBTU

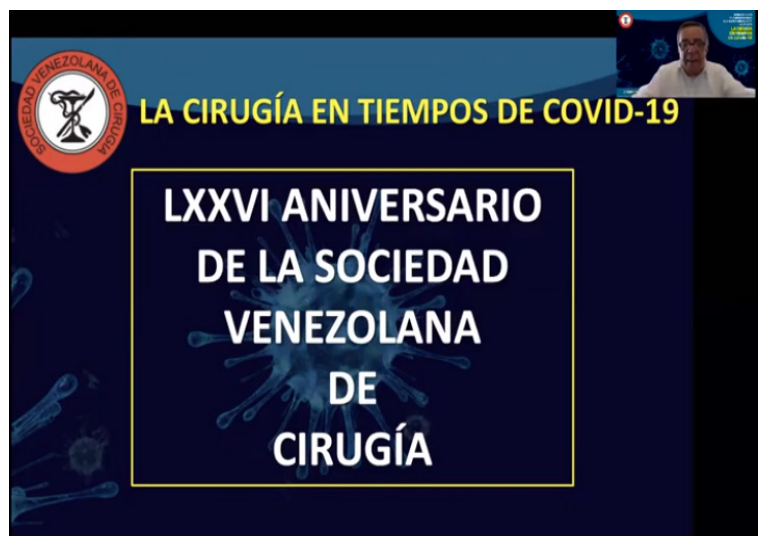

